MichU

DeptE

CenREST

$\mathrm{W}$

$88-10$
Center for Research on Economic and Social Theory CREST Working Paper

Urban Commuting Journeys are Not "Wasteful"

Michelle J. White

February, 1988

Number $88-10$

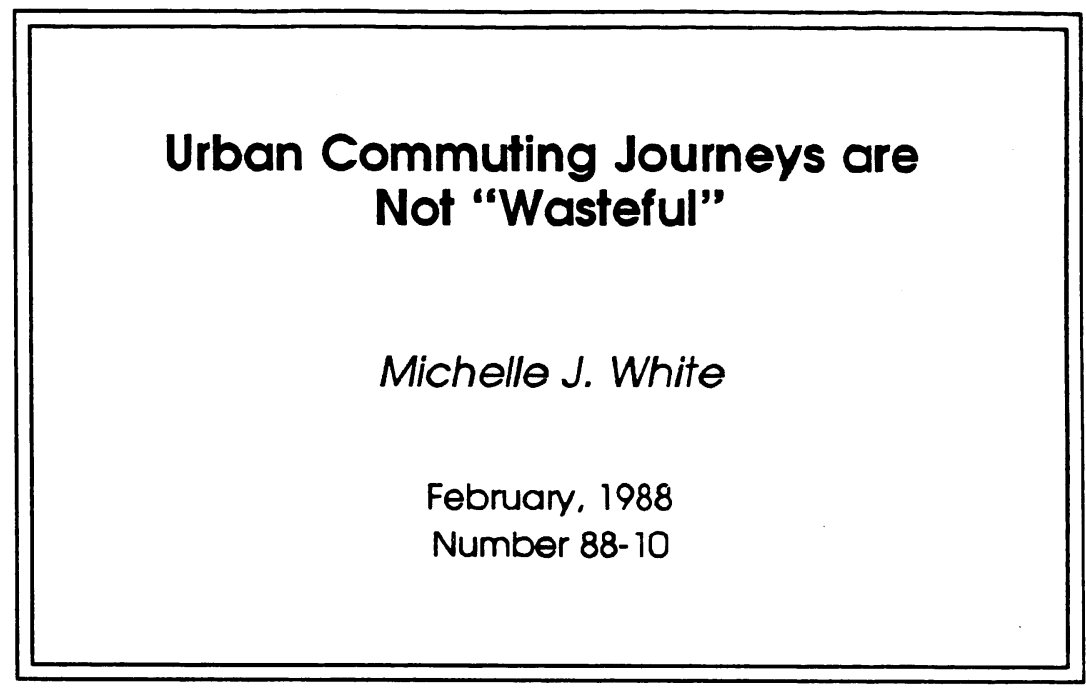

Publushed cir

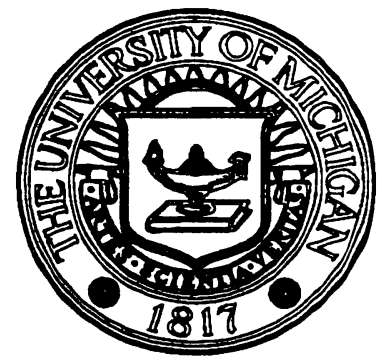

DEPARTMENT OF ECONOMICS

FEB 221989 University of Michigan Ann Arbor, Michigan 48109

The Sumner and Lama Foster Library The Eniversity of Wichngan 



\title{
Urban Commuting Journeys Are Not "Wasteful"
}

by

\author{
Michelle J. White*
}

University of Michigan 



\title{
Urban Commuting Journeys Are Not "Wasteful" \\ Michelle J. White*
}

\begin{abstract}
Hamilton (1982) first argued that urban workers' commuting journeys are so long that the monocentric urban models literature has little predictive value concerning commuting. In this paper I re-interpret the definition of "wasteful commuting" to include only the amount of commuting that could be eliminated if workers traded jobs or houses, holding fixed the existing spatial patterns of jobs and housing and the actual urban transportation network in the urban area. Using an assignment model to calculate new estimates of the amount of wasteful commuting, I find that "waste" constitutes only a minor fraction$11 \%$ - of the total amount of commuting by workers in U.S. cities, rather than the extremely high $87 \%$ figure found by Hamilton.
\end{abstract}


Do urban workers commute too much? Bruce Hamilton (1982) was the first to raise the question of whether urban workers' commuting journeys are too long or, in his terms, "wasteful." Hamilton argued that the monocentric urban model predicts that workers' commuting journeys will be minimized. To test the model, he calculated the minimum commuting journey length for the average worker in a group of U.S. cities and compared the results to the actual average commuting journey length for those workers. He assumed that any difference between the two figures was "wasteful commuting." He found that the average minimum commuting distance was only 1.1 miles, but the average distance actually commuted by workers in those cities was 8.7 miles, or nearly 8 times as great. Hamilton therefore concluded that the monocentric urban model has little predictive value concerning commuting behavior and that actual commuting behavior could be predicted just as well using an assumption that commuting is random.

Commuting behavior is a central feature of any model which purports to explain urban residential and job location choice. Hamilton's assertion that the monocentric urban model has little predictive value concerning commuting behavior therefore strikes at the heart of modern urban economics. But Hamilton made such strong and inclusive assumptions concerning the definition of "wasteful commuting" that no city whose residents determine their locations by the postulates of economic rationality would be expected to satisfy them. In this paper I calculate new estimates of the average minimum commuting journey length in a sample of U.S. cities, using a more reasonable interpretation of what urban models would predict concerning location behavior by workers and firms. Comparing the resulting estimates of minimum commuting with data on the actual commuting journey length by workers in the same cities results in new estimates of the amount of "wasteful commuting." For a sample of cities which overlaps Hamilton's, I find that only around $11 \%$ of the actual amount of commuting in urban areas is "wasteful." Thus "waste" in fact appears to be only a minor factor in explaining the commuting behavior of U.S. urban workers.

Section 1 of the paper discusses the predictions of the monocentric urban models theory concerning commuting decisions by workers. Section 2 presents the assignment model approach used here to calculate new estimates of the minimum commuting journey predicted by the monocentric urban model. 


\section{Predictions of the Monocentric Urban Model Concerning Commuting}

In the simplest monocentric urban model, all households have identical tastes and have one worker, all workers have identical jobs and earnings, and all jobs are at the CBD. Households choose their residential locations by maximizing utility functions subject to budget and time constraints. Commuting is assumed both to take time and to cost money. Residential locations are characterized by distance from the CBD, with the city assumed to be identical in all directions. Workers are willing to choose residential locations which involve longer commutes because housing prices fall with greater distance from the CBD. All commuting is on radial roads which are assumed to be ubiquitous. The average oneway commuting journey length therefore equals the average residential distance from the CBD. In the centralized employment model, which worker takes which job is irrelevant. ${ }^{1}$

Now introduce partial employment decentralization into the model, but hold other assumptions unchanged. ${ }^{2}$ Following Hamilton, I assume that the spatial patterns of employment location and of housing location are both fixed. When any jobs move out of the $\mathrm{CBD}$, the pairing of individual workers' residential and job locations becomes important. The minimum possible average commuting journey length for workers in a city occurs if the following properties hold for all workers employed at suburban jobs: (1) workers' jobs are on the same ray from the CBD as their houses and (2) their jobs are closer to the CBD than their houses. If these two conditions are satisfied for all workers, then all commuting in the urban area will be in-commuting, i.e., toward the CBD along a single ray during the home-to-work journey. There will be no out-commuting and no circurnferential commuting, i.e., no commutes which are away from the CBD during the home-to-work journey or which start on one ray from the CBD and end on another. Further if all workers in the city in-commute, then the average commuting journey length of workers in the city will be minimized.

Hamilton assumes that these two conditions are both satisfied for all workers in all cities when he calculates his estimates of the average minimum commuting distance in a city. He therefore assumes that all commuting in excess of the distance required for workers to in-commute to their jobs is "wasteful." 3 However, in actuality, when firms move out of the $\mathrm{CBD}$, they usually choose suburban locations which are concentrated at particular 


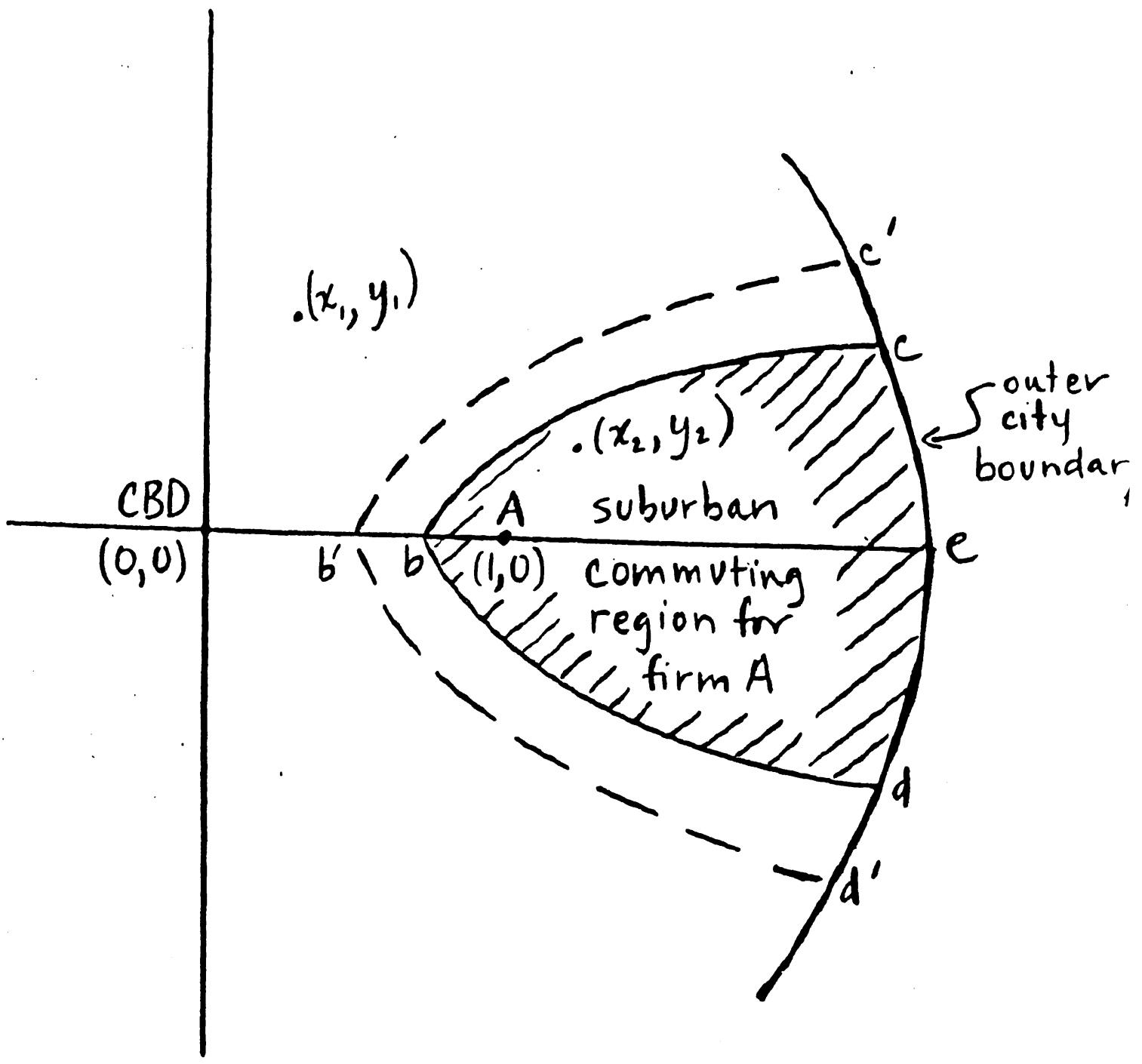

Figure 1 
suburban subcenters. This causes suburban jobs to have a different distribution around the CBD than the distribution of workers' residences. As a result, not all workers can incommute to their jobs. Under what circumstances will workers choose to commute outward or circumferentially to suburban jobs and what effect does this have on the average length of commuting journeys in the urban area?

As an example, suppose an arbitrary large firm (or group of firms) called firm $A$ moves from the CBD to a suburban location which is one mile east of the CBD. All jobs in the urban area are now located either at the CBD or at firm $A$. Figure 1 shows the CBD of the urban area at the origin of a graph and firm $A$ at $(1,0)$. The outer boundary of the city is the curve ced. Given firm $A$ 's location, only workers that live more than one mile from the $\mathrm{CBD}$ and along the $x$-axis can in-commute to it. Workers are willing to in-commute to a suburban firm if it pays a wage equal to the wage at the CBD minus workers' savings in commuting costs from working at the suburban firm. Assume that the wage per day at the $\mathrm{CBD}$ is $w^{*}$, and that commuting costs are $\gamma$ per mile round trip. Then firm $A^{\prime} \mathrm{s}$ in-commuting wage is $w^{*}-\gamma$. At this wage, only workers that can in-commute to firm $A$ will be willing to work there. Therefore firm $A$ 's in-commuting region consists solely of workers living along the line segment $A e$.

However if firm $A$ is large, then it may demand more workers than live along the line segment $A e$. Then to induce some workers to out-commute or commute circumferentially to the firm, it must raise its wage above $w^{*}-\gamma$. Suppose firm $A$ offers a wage of $w^{\prime}$, which is above the in-commuting wage, but below the CBD wage, or $w^{*}-\gamma<w^{\prime}<w^{*}$. Also suppose the urban area has straight-line roads connecting all residences to all workplaces. Finally, assume that all households in the urban area consume the same amount of housing. ${ }^{4}$

The rise in wages paid by firm $A$ increases the size of the commuting region from which workers are willing to commute to firm $A$. Workers are indifferent between commuting to two different job locations when the wages at both job locations minus commuting costs are equal. Therefore the equation defining the boundary of firm $A$ 's commuting region is

$$
w^{*}-\gamma\left(x^{2}+y^{2}\right)^{1 / 2}=w^{\prime}-\gamma\left((x-1)^{2}+y^{2}\right)^{1 / 2},
$$

where $x$ and $y$ are the coordinates of a worker's residential location on the graph of the 
87-29: Hal R. Varian, "Optimal Tariffs and Financial Assets" April, 1987.

87-30: Jonathan Cave, Stephen W. Salant, "Cartels That Vote: Agricultural MarketingBoards and Induced Voting Behavior" August, 1987.

87-31: Stephen W. Salant, Donald H. Negri, "Pastures of Plenty: When is the Standard Analysis of Common Property Extraction Under Free Access Incorrect?" July 10, 1987.

87-32: Stephen W. Salant, “When is Inducing Self-Selection Sub-optimal for a Monopolist?" February, 1987.

87-33: Stephen W. Salant, "Treble Damage Awards in Private Lawsuits for Price-Fixing" August, 1987.

87-34: Stephen W.Salant, Roy Danchick, "Air Force Academy Attrition: A New Perspective on the College Dropou t Problem" August, 1987.

87-35: Stephen W. Salant, Eban Goodstein, "Committee Voting Under Alternative Procedures and Preferences: An Experimental Analysis" April 20, 1987.

87-36: Robert B. Barsky, Jeffrey A. Miron, "The Seasonal Cycle and the Business Cycle" June, 1987.

87-37: Robert B. Barsky, N. Gregory Mankiw, Jeffrey A. Miron and David N. Weil, "The Worldwide Change in the Behavior of Interest Rates and Prices in 1914" July, 1987.

87-38: Jeffrey K. MacKie-Mason, "Taxes, Information and Corporate Financing Choices" April, 1986.

87-39: Avery Katz, "The Effect of Frivolous Lawsuits on the Settlement of Litigation" August, 1987.

88-1: Carol A. Jones, Suzanne Scotchmer, "The Social Cost of Uniform Regulatory Standards in a Hierarchical Government" December, 1987.

88-2: Ted Bergstrom, Judy Roberts, Dan Rubinfeld, Perry Shapiro, "A Test for Efficiency in the Supply of Public Education" December 12, 1987.

88-3: Mark Bagnoli, J. Bradley Barbeau, "Competition and Product Line Choice" February, 1988.

88-4: Severin Borenstein, Paul N. Courant, "How to Carve a Medical Degree: Human Capital Assets in Divorce Settlements" December, 1987.

88-5: Mark Bagnoli, Stephen W. Salant, Joseph E. Swierzbinski, "Pacman Refutes the Coase Conjecture: Durable-Goods Monopoly with Discrete Demand" January, 1988.

88-6: Jonathan Cave, Stephen W. Salant, “A Median Choice Theorem” December 29, 1987.

88-7: Mark Bagnoli, Naveen Khanna, "Why Are Buyers Represented by Seller's Agents When Buying a House?" December, 1987.

88-8: Mark Bagnoli, Roger Gordon, Barton L. Lipman, "Takeover Bids, Defensive Stock Repurchases, and the Efficient Allocation of Corporate Control" October, 1987.

88-9: Mark Bagnoli, Barton L. Lipman, "Private Provision of Public Goods can be Efficient" November, 1987.

88-10: Michelle J. White, "Urban Commuting Journeys are Not "Wasteful"” February, 1988.

88-11: Avery Katz, "A Note on Optimal Contract Damages When Litigation is Costly" February, 1988.

88-12: Ted Bergstrom, Jeff MacKie-Mason, "Notes on Peak Load Pricing” February, 1988.

88-13: Jerry A. Hausman, Jeffrey K. MacKie-Mason, "Price Discrimination and Patent Policy" February, 1988 . 


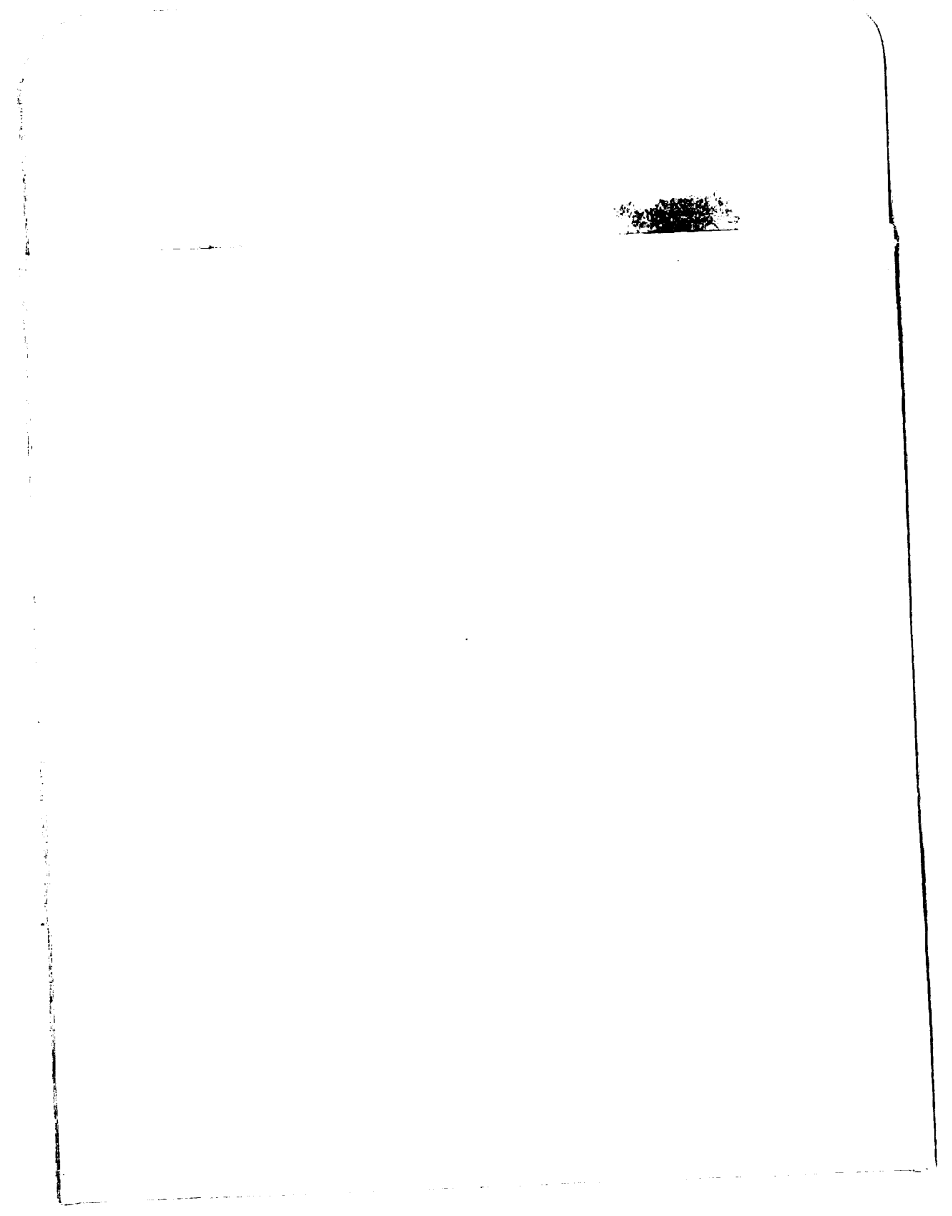


